Agata Komorowska

Uniwersytet Jagielloński

agata.komorowska@uj.edu.pl

\title{
Recursos cohesivos basados en elementos deícticos
}

\section{Resumen:}

En el presente artículo se analiza el papel de la deíxis en los procedimientos cohesivos empleados en las formas de comunicación por escrito. Se estudia la presencia de los elementos deícticos en la cohesión de los distintos niveles discursivos, así como la persistencia de los valores originales de tales elementos deícticos en determinadas unidades, como los marcadores discursivos o las expresiones de correferencia.

Palabras clave: cohesión, deíxis, marcadores discursivos, anáfora

\begin{abstract}
:
Cohesive Resources Based on Deictics Elements

This article examines the role of deixis in cohesive devices used in written communication forms, focusing on the use of deictic elements for cohesion at various discourse levels, as well as the persistence of original meanings of such deictic elements in selected units, e.g. discourse markers and coreferential expressions.
\end{abstract}

Keywords: cohesion, deixis, discourse markers, anaphor 


\section{Introducción}

Desde que los investigadores del lenguaje trasladaron su centro de interés a unidades lingüísticas más complejas que la oración (enunciados, discursos, textos), uno de los aspectos que suelen analizar en sus investigaciones es el conjunto de características lingüísticas, paralingüísticas, pero también extralingüísticas, de las que depende la percepción de varias secuencias comunicativas como un único conjunto. El factor clave en este sentido es la forma en que se organizan y relacionan dichas secuencias, lo cual constituye la base de la cohesión.

En ocasiones la cohesión se ha considerado equivalente a la coherencia, en cuyo caso estos dos términos se han empleado indistintamente, o bien se ha introducido uno más, el de conectividad o conexión (véase Lewandowski, 1995: 58-59; van Dijk 1988, entre otros). Sin embargo, en la actualidad, son mayoría los que prefieren separar los mencionados conceptos, optando por la palabra coherencia para referirse a la concordancia entre el contenido del mensaje emitido y su adecuación a la realidad extralingüística, mientras que el término cohesión queda reservado para la concordancia lingüística y lógica de los elementos constituyentes de la secuencia comunicativa. Esta postura de clara distinción entre ambos conceptos es la que adoptamos en el presente trabajo, cuyo objetivo consiste en examinar los mecanismos cohesivos basados en la deíxis.

Dicha relación entre los deícticos y sus distintos empleos, por una parte, y la cohesión, por otra, se evoca, a veces implícitamente, en múltiples trabajos lingüísticos, principalmente en los dedicados al análisis del discurso y la textualidad con especial atención a los temas del contexto y el cotexto (Lozano, Peña-Marín, Abril, 1993: 49-50; Zydek-Bednarczuk, 2005: 236-238). Sin embargo, en la mayoría de los casos, tal relación no se analiza en profundidad; los autores se limitan más bien a señalar su existencia, enumerando, en ocasiones, determinados mecanismos cohesivos con deícticos.

Además, por lo general, el foco de interés suele ponerse en la naturaleza indexical de los deícticos, conforme al planteamiento semiótico de Peirce (1997), coincidente con el concepto de campo mostrativo 
de Bühler, quien comparaba el funcionamiento de los demostrativos con el de los postes indicadores (2004 [1934]: 82). Es cierto que la capacidad de mostrar, tan esencial para los elementos objeto del presente estudio, reflejada incluso en su nomenclatura ${ }^{1}$, contribuye, de forma nada desdeñable, a la organización de la estructura discursiva, principalmente mediante los procedimientos anafóricos. No obstante, es llamativo que no suele abordarse en dicho contexto el papel del egocentrismo, rasgo distintivo inherente a la deíxis (Vicente Mateu, 1994).

Esa vinculación al yo del acto comunicativo, que, dicho sea de paso, no siempre tiene que coincidir con el emisor del mensaje ${ }^{2}$, nos parece digna de examinarse en el uso de los recursos cohesivos, empleados en el lenguaje escrito. Más aún, si se tiene en cuenta que en los textos escritos la comunicación no se desarrolla cara a cara, por lo cual puede producirse una mayor o menor $^{3}$ difuminación de las figuras de los interlocutores; por añadidura, el mismo proceso comunicativo tiende a repetirse, motivo por el que en cada caso puede cambiar el receptor del mensaje. Ambas circunstancias desestabilizan las coordenadas espacio-temporales de la enunciación y, parcialmente, las personales, lo cual tiene impacto en la interpretación de las fórmulas deícticas.

Por consiguiente, en este trabajo nos planteamos como objetivos presentar, en primer lugar, una revisión de los recursos cohesivos basados en elementos deícticos y, a continuación, averiguar si la deíxis utilizada en textos escritos como mecanismo cohesivo puede

${ }^{1}$ Del griego deixis 'mostración'.

2 Todo lo contrario: son los elementos deícticos los que tienen el poder de determinar las coordenadas temporales, espaciales y personales del acto comunicativo, independientemente de la realidad extralingüística.

${ }^{3}$ Ello depende del género discursivo empleado. En las cartas son explícitas las marcas lingüísticas por las que se manifiestan el emisor y el destinatario del mensaje; en los trabajos científicos el emisor suele esconderse detrás del denominado plural de modestia; mientras que las noticias periodísticas suelen estar redactadas en tercera persona gramatical, y las únicas manifestaciones del emisor del mensaje suelen adquirir la forma de referencias temporales de interpretación deíctica (ayer o el uso de los tiempos verbales). 
fundamentarse en su primordial referencia al yo, rasgo constituyente la esencia de dicho fenómeno. Con ello esperamos contestar a la pregunta de hasta qué punto la cohesión, además de basarse en relaciones léxico-gramaticales, tiene naturaleza pragmática por su anclaje en el contexto enunciativo.

\section{Cohesión del texto}

Beaugrande y Dressler (1990: 19-32) subrayan que, para que pueda hablarse de textualidad, un conjunto formado por una serie de secuencias comunicativas tiene que incluir entre sus propiedades la cohesión, la coherencia, la intencionalidad, la aceptabilidad, la situacionalidad, la intertextualidad y la informatividad. Obviamente, para los fines de este artículo, el concepto más importante es el de cohesión. Tal y como se ha mencionado, para evitar posibles confusiones terminológicas, es importante diferenciarlo del de coherencia, aunque, al fin y al cabo, ambas propiedades mantienen una relación convergente en su común finalidad de garantizar lo que Beaugrand y Dressler llaman la estabilidad del texto (ibidem: 72).

En cuanto a la definición general, la cohesión, según los mencionados lingüistas, se debe entender como la continuidad originada por la interdependencia gramatical de los componentes de la superficie textual (ibidem: 20,72), por lo cual suele vincularse a reglas y estructuras sintácticas. A su vez, Halliday y Hassan (1984: 4) describen la cohesión en términos semánticos, al señalar que dicho fenómeno tiene lugar si un elemento del discurso se interpreta en función de otro, esto es, si uno presupone otro, parte ambos del mismo texto.

En el presente trabajo adoptaremos una definición que combina el aspecto sintáctico con el semántico: conforme piensa Duszak (1998: 92), la cohesión es un fenómeno semántico-temático, con manifestaciones formales en la estructura de la oración, entre las cuales se encuentra la recurrencia, que, en opinión de Bellert (1971: 49), es requisito de obligado cumplimiento para la cohesión. Bajo cohesión se incluye una serie de mecanismos por los que se manifiesta 
la continuidad discursiva y, que, a la vez, contribuyen a una correcta interpretación del mensaje.

Asimismo, es importante subrayar que la cohesión no solo se produce en el nivel oracional o entre enunciados, sino que puede entenderse como un concepto global referido al texto en su conjunto. En otras palabras, dicha propiedad está presente tanto en el nivel de la microestructura como en el de la macroestructura, según la dicotomía de van Dijk (1988) ${ }^{4}$.

Es preciso añadir que el empleo de recursos cohesivos es especialmente necesario en el lenguaje escrito. En la lengua oral, si bien la cohesión siempre es recomendable, sobre todo en el nivel gramatical, se manifiesta con otros recursos, no tan patentes. Cualquier transcripción de una conversación oral espontánea constituye una muestra de que, a pesar de los múltiples defectos gramaticales (anacolutos, truncamientos, recurrentes faltas de concordancia morfosintáctica) que se dan, el contexto situacional compartido por los interlocutores, junto con los recursos paralingüísticos y extralingüísticos, ayudan a conseguir la plena comprensión del mensaje transmitido. Además, en una conversación cara a cara, los interlocutores intercambian constantemente los papeles de emisor y de destinatario, de ahí que en todo momento sea posible aclarar las dudas surgidas en el curso de la misma o, si es necesario, volver atrás en el contenido conversacional con el fin de explicar lo mal entendido.

No ocurre lo mismo con las formas de comunicación por escrito, en las que el proceso comunicativo se desarrolla de forma lineal, continua $\mathrm{y}$, hasta cierto punto, unilateral. A saber: las secuencias comunicativas suelen ser más largas y no se produce intercambio de papeles discursivos entre los interlocutores, por lo cual son muy escasas las posibilidades de rectificación una vez concluida la emisión del mensaje. Ante tales circunstancias, el emisor tiene que esforzarse por que el acto de comunicación culmine con éxito, con una correcta interpretación por

${ }^{4}$ Las definiciones de ambos conceptos, retomados, entre otros, por Fuentes Rodríguez (1996), evolucionan conforme avanzan las investigaciones de Van Dijk. 
parte del destinatario. Simplificando, podría decirse que para conseguir dicho objetivo el emisor debe cumplir con el requisito mínimo de no dificultar la comprensión, o, mejor aún, con el de facilitar la misma. Para ello dispone de toda una serie de mecanismos, entre los cuales destacan los recursos destinados a reforzar el aspecto cohesivo de la microestructura y la macroestructura textuales.

Varios son los casos en los que optimiza la comprensión del mensaje y, por consiguiente, fomenta una comunicación exitosa el uso de los elementos que garantizan la adecuada cohesión, entendida como continuidad o función integradora entre las partes que componen el texto en cuestión, "para que las mismas queden urdidas en un todo" (Escavy Zamora, 2009: 185).

En lo que se refiere a la cohesión en el nivel de la microestructura discursiva, es necesario mencionar, en primer lugar, las relaciones morfosintácticas, responsables de la corrección estilístico-gramatical. Se trata de determinadas reglas cuya aplicación garantiza que, como mínimo, no se complique el proceso de entendimiento, pero adicionalmente tienen como objetivo el de reforzar la estabilidad y la economía textual $^{5}$, referidas por Beaugrand y Dressler (1990: 73-74). En segundo lugar, es importante aludir a los siguientes mecanismos cohesivos, utilizados en el nivel de enunciado: la recurrencia, el paralelismo, la paráfrasis y la elipsis (ibidem); en este contexto Casado Velarde enumera también la sustitución (1993: 20-21), que, no obstante, puede integrarse bajo el concepto de recurrencia, cuyas manifestaciones son los procedimientos referenciales endofóricos, como la anáfora y la catáfora ${ }^{6}$.

A su vez, la cohesión macroestructural suele conseguirse con el uso de los marcadores discursivos ${ }^{7}$, en particular los conectores, mediante los cuales el emisor es capaz de mostrar una determinada relación

${ }^{5}$ En español, un ejemplo de ello podría ser la habitual omisión del pronombre sujeto.

${ }^{6}$ En el presente trabajo nos serviremos únicamente del término anáfora, más frecuente en el contexto deíctico.

${ }^{7}$ En la distinción entre los marcadores y los conectores seguimos a Portolés (2011), quien percibe los marcadores como categoría que engloba los conectores. 
incluso entre fragmentos textuales aparentemente sin conexión o hasta contradictorios (como es el caso de los marcadores por otra parte o por el contrario).

En ambos niveles, el de la micro- y el de la macroestructura, los deícticos constituyen un elemento cohesivo clave.

\section{Cohesión y deíxis}

Antes de pasar al estudio de los recursos cohesivos basados en elementos deícticos, conviene recordar algunos datos básicos relacionados con la deíxis. En este sentido, Rauh (1983) habla de tres puntos capitales: la determinación deíctica, las dimensiones deícticas y los usos de expresiones deicticas.

La determinación deíctica equivale al significado simbólico de los elementos deícticos, conforme al cual la deíxis tiene por función primordial la de designar referentes para determinadas expresiones lingüísticas, basándose en las coordenadas personales, temporales y espaciales de la situación comunicativa. El punto de partida para interpretar dichas expresiones es el punto cero, llamado por Bühler origo, cuyos integrantes son el yo, el aqui y el ahora del acto comunicativo (2004 [1934]: 105-106). Se trata de palabras de referencia variable, esto es, dependientes del contexto situacional.

Las dimensiones deícticas clásicas son tres: la deíxis personal (a través de pronombres personales o de la categoría de persona en las formas verbales), la deíxis temporal (cuyos exponentes son la categoría de tiempo en las formas verbales o los adverbios temporales) o la deíxis espacial (con los demostrativos) ${ }^{8}$.

En lo que se refiere a los usos de las expresiones deícticas, siempre se menciona la mostración ad oculos (Bühler, ibidem), denominada por Fillmore la deixis gestual (1997: 62), esto es, la remisión directa a la situación comunicativa, en ocasiones reforzada con gestos (1). En la mayoría de los trabajos sobre la deíxis, suele hablarse también de los

${ }^{8}$ Obviamente, estos solo son algunos componentes de la larga lista de los elementos deícticos. 
procedimientos deícticos empleados con el fin de efectuar una mostración intratextual, que recibe el nombre de deíxis anafórica (Bühler, op. cit., Fillmore; op. cit.) (2). En varios casos, se señalan asimismo los usos basados en una mostración metafórica, en los que los deícticos hacen referencia, entre otros elementos, a circunstancias guardadas en la memoria de los interlocutores. Recibe esta deíxis la denominación de deíxis am phantasma o simbólica (Bühler, op. cit.; Fillmore, op. cit.) (3):

(1) Esta camisa me gusta mucho.

(2) La camisa era roja. Y, además, esa era la que más me gustaba.

(3) Aquella camisa me recordaba mi infancia.

Para comentar el papel de la deíxis en la cohesión textual es preciso comenzar por el nivel microestructural, en el que lo más obvio es la concordancia morfosintáctica, dependiente del correcto uso de los deícticos. En el nivel microestructural se da también otro tipo de manifestación de la cohesión basada en elementos deícticos: la concordancia semántica entre las temporalidades verbales y las realidades designadas por las mismas. A saber: si un texto se refiere a acontecimientos pasados, deberían emplearse tiempos con valor de anterioridad, como el pretérito, anterior al origo, o el copretérito, tiempo simultáneo a un punto anterior al origo (Rojo, Veiga, 1999: 2883) (4).

(4) En 1939 estalló la Segunda Guerra Mundial.

Dicha concordancia deíctica temporal es de obligado cumplimiento tanto en el nivel del discours como en el de la histoire benvenistianos $(1966)^{9}(5)$. Si se rompe, ocurre lo mismo que en la violación de las máximas de Grice (1980): suele tratarse de algún tipo de implicación, es decir, de una estrategia pragmática que, en tal situación, se basa en el desplazamiento del origo. Esto es lo que tiene lugar cuando los hechos, que se presentan como simultáneos al origo, son en realidad

${ }^{9}$ En ese sentido, el polaco es mucho menos estricto: en el discurso indirecto el enunciado que introduce los acontecimientos contados puede empezar con un verbo de comunicación en una forma que indica anterioridad al origo, $\mathrm{y}$, sin embargo, la historia referida puede situarse temporalmente como si coincidiera con el ahora del acto de enunciación. 
anteriores al mismo. Dicha estrategia se observa en el denominado presente histórico (6) o en los pies de foto de los periódicos, en los que incluso se produce un desfase temporal entre la temporalidad utilizada y los correspondientes adverbios de tiempo (7).

(5) Dijo que iba siempre vestido de rojo.

(6) En 1939 estalla la Segunda Guerra Mundial.

(7) Ayer los manifestantes protestan en Madrid.

En segmentos comunicativos más largos, la cohesión textual es todavía más importante, debido a que sus mecanismos garantizan la relación entre oraciones, enunciados o, incluso, fragmentos enteros, de ahí que sea muy frecuente otro procedimiento cohesivo deíctico: la deíxis anafórica ${ }^{10}$.

La anáfora es especialmente frecuente en el lenguaje escrito y puede realizarse tanto en el nivel microestructural como en el macroestructural. Se trata de una especie de mostración intratextual, que, mediante la correferencia efectuada por los pronombres personales, los posesivos o los pronombres y adverbios demostrativos, incrementa la cohesión del mensaje transmitido. Dicha cohesión, garante de una mayor integridad discursiva, es posible, en primer lugar, gracias al entramado de relaciones que construyen los deícticos anafóricos entre las diversas partes del texto. En segundo lugar, no es de desdeñar el hecho de que gracias a la anáfora no se produzcan reiteraciones innecesarias y de que debido a ese ahorro de recursos lingüísticos se consiga una mayor claridad del mensaje ${ }^{11}(8)$.

(8) En 1903, al cumplir los veinte, la vida de Gabriele cambió por completo. Ella y Adrienne fueron confiadas a una importante mercería del lugar, A Sainte Marie, especializada en ajuares y canastillas, como aprendizas. Su hermana Julia, por ser la mayor, ayudaba a sus abuelos en los

${ }^{10}$ No existe unanimidad acerca de si se puede considerar la anáfora como parte del fenómeno deíctico (véase, por ejemplo, García Salido, 2011).

${ }^{11}$ A diferencia del lenguaje escrito, este último punto no es necesariamente cierto en conversaciones orales, en las que las múltiples anáforas con pronombres personales pueden llevar incluso a confusión. 
mercados (Urrea, Inmaculada: Coco Chanel. La revolución de un estilo. Barcelona: EIUNSA, 1997).

Cabe preguntarse en este momento por el papel del origo en los procedimientos cohesivos basados en los deícticos anafóricos, que efectúan una referencia de naturaleza intratextual. En principio, podría pensarse que en un proceso comunicativo efectuado por el canal escrito se prescinde de la remisión al contexto situacional. Sin embargo, no es así, aunque la remisión al origo no es igual a la efectuada en la deíxis ad oculos y, además, puede presentar grados de vinculación contextual distintos.

Para establecer el ego-hic-nunc en el uso anafórico de los elementos deícticos, el primer problema que se plantea es la determinación de las coordenadas espacio-temporales comunes al emisor y el destinatario del mensaje que participan en el acto comunicativo por escrito, Ello se debe a que la comunicación se realiza en tiempo diferido, los interlocutores suelen encontrarse en sitios diferentes y la figura del destinatario es variable.

Ante dicha falta de coincidencia espacio-temporal y la intervención de destinatario no siempre identificable con precisión (ni siquiera por el propio emisor, puesto que puede asumir el papel de receptor cualquiera que tenga acceso al texto en cuestión) son posibles dos estrategias discursivas. En la primera se amplía el concepto de ahora de forma que pueda abarcar un intervalo de tiempo abierto (mediante expresiones del tipo de en la actualidad o las formas del denominado presente atemporal), mientras que el concepto de aqui se interpreta de forma lo suficientemente extensa como para que pueda incluir el lugar en el que se ubica el hipotético lector en el momento de la recepción del mensaje, sin dejar de coincidir con el aquí del emisor (caso del aquí equivalente a en este país/continente/mundo).

La otra estrategia consiste en desplazar el origo espacio-temporal hacia los ámbitos locativo-temporales deseados, que no coinciden con el lugar y momento del acto enunciativo. Principalmente, el desplazamiento afecta a las coordenadas de tiempo cuando el cambio de óptica sobre el punto cero de las relaciones temporales requiere una 
reinterpretación pragmática de las formas verbales utilizadas, como se ha visto en los ejemplos con el presente histórico o los pies de foto.

Esa segunda estrategia es la que se observa en la deíxis anafórica en los textos escritos, así como en otros usos de expresiones deícticas con función cohesiva. El desplazamiento del origo es posible gracias el hecho de que el emisor, que en realidad emite su mensaje con significativa anterioridad respecto al momento de recepción del mismo y encontrándose en un lugar diferente al de ubicación de su posible interlocutor, sitúa en el propio texto las coordenadas espacio-temporales del acto comunicativo. De esta forma, el texto se convierte en un espacio físico compartido por los interlocutores, en el que la linealidad de la comunicación permite crear también la ilusión de un origo temporal y espacial común.

La linealidad comunicativa implica además la constante movilidad del origo espacio-temporal situado en el texto. A saber: al escribir su mensaje el emisor va avanzando por los consecutivos segmentos textuales y, de la misma forma, el origo va desplazándose con él, trazando la ruta textual seguida posteriormente por los receptores. En otras palabras, los participantes del acto comunicativo, al moverse por el mismo espacio textual (en el proceso de producción o de recepción del texto), tendrán en cada momento los mismos fragmentos del texto por delante y los mismos por detrás. Ello permite interpretar con precisión los deícticos espaciales o temporales basándose en una distancia real en el plano textual: este y ese se refieren a lo recién emitido, o lo que no se tardará en emitir; mientras que aquel, a lo más alejado ${ }^{12}$.

La interpretación de los deícticos a partir del origo textual es especialmente visible en el recurso cohesivo denominado por Lamíquiz anáfora dual (1983: 307-308), en la que siempre se emplean dos demostrativos anafóricos: este, de cercanía, y aquel, de lejanía (9):

12 A su vez, mediante los mismos demostrativos anafóricos se pueden expresar la lejanía y la proximidad no literales, esto es, mentales, aunque esta vez el origo adoptado no es intratexual debido a que toma como punto de referencia al emisor del mensaje, aunque sin aludir de forma directa a sus coordenadas espacio-temporales. El objetivo es simplemente expresar una mayor o menor distancia mental del emisor frente a determinados fenómenos. 
(9) Mario y Juan eran muy amigos; carpintero este y sastre aquel.

Otros dos mecanismos anafóricos, basados en los demostrativos y el origo endofórico son la anáfora etimológica y la anáfora difusa (Fernández Ramírez, 1987: 126). En la etimológica, el pronombre demostrativo acompaña un sustantivo ya empleado con anterioridad, o uno que posee la misma raíz o un significado parecido al del nombre anterior (10). La difusa, denominada también oracional o, en la terminología de González Ruiz, conceptual o de encapsulación (2009), consiste en emplear el demostrativo junto a un sustantivo utilizado por primera vez en sustitución conceptual de una palabra o un grupo de palabras ya usados en el discurso (11). En ambos casos, los deícticos tienen como función principal relacionar distintos fragmentos con el fin de reforzar la cohesión textual, así como hacer valer la insistencia indicadora mediante el uso de los demostrativos de cercanía.

(10) Dos semanas después de su última comparecencia, López reapareció ayer para hacer una "valoración serena" del pacto con el PP y reiterar que será "el lehendakari de todos". Ante las críticas de los nacionalistas a esta alianza, López subrayó que (...) (El Mundo, 5.04.2009: 5)

(11) "El presidente del Gobierno no cuenta con un entrenador personal, ni tiene un plan especifico para hacer deporte y mantenerse. Sólo practica footing cuando su agenda se lo permite, aunque procura salir a correr al menos dos o tres días por semana". Para Zapatero, esta afición le permite (...) (El Mundo, suplemento Crónica, 28.12.2008: 6).

La cohesión basada en el origo inserto en el texto se observa también en el nivel macroestructural. Su ejemplo por excelencia es la denominada deíxis discursiva (Fillmore, 1997: 61) o deíxis textual (Eguren, 1999: 97), en la que se efectúan referencias a secuencias discursivas anteriores o posteriores, localizables gracias al origo intratextual común al emisor y el receptor del mensaje, como en el ejemplo (12):

(12) En páginas anteriores queda bien claro lo que significa la muerte de un ser humano en cualquier momento (Jiménez Vargas, J., López García, 
G., ¿A qué se llama aborto?, Magisterio Español; Prensa Española, Barcelona, 1975).

Hasta cierto punto, se detectan similitudes entre la deíxis discursiva y la anáfora. No obstante, en la deíxis discursiva no se realiza ningún tipo de correferencia y, además, su naturaleza es metalingüística, puesto que las referencias realizadas siempre conciernen a unidades discursivas (en el presente capítulo o en el párrafo siguiente). Debido a lo anterior y haciéndonos eco de algunas opiniones según las cuales la anáfora no forma parte del fenómeno deíctico (Escavy Zamora, 1987; Eguren, 1999; entre otros), podríamos afirmar que la deíxis discursiva es el único caso de verdadera deíxis en el plano textual, puesto que la referencia intratextual que efectúa es la que más se parece a la mostración gestual física, frente a la correferencia, que, en última instancia, siempre remite a un referente extratextual.

Volviendo al tema de la cohesión, el elemento fundamental tanto en el caso de la anáfora como en el de la deíxis discursiva parece ser su específico origo textual, que tiene una influencia muy concreta en el refuerzo de la cohesión discursiva. Por una parte, de forma global ofrece un punto de conexión adicional, en el que se anclan los distintos elementos y fragmentos textuales, lo cual cumple una función integradora. Por otra, la referida precisión interpretativa, principalmente en la anáfora con demostrativos, se traduce en una especie de apuntamiento, gracias al cual es posible focalizar la atención del receptor en determinadas partes del texto.

Finalmente, al hablar del papel de los deícticos en la cohesión, no se puede hacer caso omiso de los marcadores discursivos, especialmente de los conectores, elementos por excelencia de refuerzo de la integridad textual, que ordenan y relacionan las distintas partes del discurso para guiar así al lector en la interpretación de la información transmitida.

Los marcadores y, en especial, los conectores constituyen los pilares en los que se sustentan la estructura y la organización del texto. Los deícticos, con su capacidad indicadora, cumplen de forma perfecta dichas funciones; por tanto, no es de extrañar que formen parte de las 
citadas unidades lingüísticas, si bien su referencia al origo, intra- o extratextual, se ve debilitada, parcialmente, por el hecho de que se trata de fórmulas lingüísticamente fosilizadas, en cuyo caso, el significado original suele atenuarse, aunque no desaparece por completo.

Eso es lo que se observa en los conectores tanto consecutivos como contraargumentativos basados en los deícticos temporales (entonces, antes bien, ahora bien), en cuyos casos se ven debilitados los valores típicos de la deíxis, como son la remisión al origo o el apuntamiento preciso (en textos escritos, hacia elementos discursivos determinados). Fuentes Rodríguez (1996: 21) percibe una ligera referencia deíctica en el conector ahora (bien), interpretándolo como forma abreviada de voy a decir ahora otra cosa que va en sentido contrario, pero en realidad el significado dominante es el de contraargumentación, si bien, con referencia a lo que acaba de exponerse.

Dicha pérdida de significados primarios en los citados deícticos temporales no es nada extraño debido a que se trata de marcadores utilizados con el fin de entrelazar los distintos fragmentos del discurso y, al mismo tiempo, guiar al receptor en la interpretación del mensaje. Como ambas funciones están fusionadas en un solo elemento lingüístico, en algún momento el significado original empieza a debilitarse frente a las nuevas funciones discursivas asumidas. Por ese motivo, en los marcadores basados en deícticos temporales, a pesar de que su capacidad para relacionar elementos se origina en su valor mostrativo, la referencia al origo es prácticamente inexistente.

No ocurre lo mismo con los deícticos espaciales que, en su papel de conectores, forman parte de expresiones analíticas. Gracias a esa estructura compleja, el deíctico puede mantener su valor original, mientras los elementos acompañantes asumen el valor lógico del marcador en cuestión, como puede ser el de ilación en el giro de ahí (de 'procedencia'; ahi 'mostración, remisión a algo relativamente cercano al origo intratextual').

Otra explicación es la ofrecida por la Real Academia Española (2009: 2366), que, al analizar determinados conectores adverbiales, sostiene que deben su valor consecutivo a la gramaticalización de un vínculo deíctico. 
Como consecuencia de esta persistencia deíctica, además de anclar entre sí y, hasta cierto punto, en el origo intratextual las distintas partes del texto, los marcadores con demostrativos presentan una mayor capacidad de focalizar determinada información, precisamente gracias a la naturaleza indexical de los demostrativos. Si comparamos los siguientes enunciados, veremos que el sentido de la frase es el mismo $\mathrm{y}$, sin embargo, en la fórmula con el demostrativo (13) la atención del lector permanece centrada en la secuencia precedente, mientras que en el caso del conector sin deícticos (14) el foco atención, como es natural, se traslada al fragmento posterior al mismo ${ }^{13}$.

13) Esta es la clave para no perder la confianza de los usuarios, de ahí que se insista en no vender la información personal a terceros.

14) Esta es la clave para no perder la confianza de los usuarios; $\underline{\text { en }}$ consecuencia, se insiste en no vender la información personal a terceros.

Por último, es importante destacar que la mostración efectuada mediante los marcadores discursivos demostrativos se sitúa entre la anáfora y la deíxis textual ${ }^{14}$. En lo que se refiere a los rasgos anafóricos, es cierto que los marcadores realizan la referencia a un elemento previamente aparecido en el texto. No obstante, contrariamente a los procedimientos anafóricos, los marcadores discursivos no se basan en la correferencia, sino que apuntan hacia ideas y conceptos más desarrollados o, incluso, hacia fragmentos enteros del texto, por lo cual extralingüísticamente no son identificables de forma unívoca. Sus antecedentes, complejos, o bien se pueden desglosar en varios referentes, o bien no tienen referencia concreta. De hecho, eso es lo que diferencia este tipo de mostración de la mencionada anáfora difusa, en la que la referencia del anafórico coincide con la de su antecedente.

13 Portolés Lázaro y Martín Zorraquino (1999: 4104) subrayan esta característica en su análisis del conector en consecuencia, afirmando que dicho conector "permite el paso de causa a efecto y no al revés".

${ }^{14}$ Eguren (1999: 937) señala la existencia de tales ocurrencias limítrofes al hablar de la referencia realizada por la forma lo, p.ej. No me lo puedo creer. En nuestra opinión, no es casualidad, si se tiene en cuenta la etimología demostrativa de la forma $l o$. 
A su vez, la similitud entre los conectores u otros marcadores discursivos basados en deícticos, por una parte, y la deíxis discursiva, por la otra, reside en que aquellos y esta permiten señalar fragmentos textuales extensos con el fin de reforzar la integridad textual. Pero, de nuevo, la referencia realizada no es del mismo tipo. La deíxis discursiva remite ad oculos a elementos físicos del texto (15), mientras que los conectores con deícticos remiten al contenido presentado en tales fragmentos (16).

(15) En los capitulos siguientes hablaremos de más casos de este tipo.

(16) No hemos podido presentar todos los detalles del tema en cuestión, por eso, no nos vemos capacitados para presentar opiniones tajantes.

\section{Observaciones finales}

Acabamos de presentar un panorama de los recursos lingüísticos cohesivos basados en elementos deícticos, centrándonos principalmente en las formas de comunicación realizadas a través del canal escrito.

Hemos observado que en el nivel microestructural los deícticos desempeñan un papel significativo en la cohesión gramatical (concordancias morfosintácticas de persona) o semántica, en su mayoría referencial (el caso de las temporalidades, coincidentes con momentos anteriores, simultáneos o posteriores al momento de la enunciación).

En el plano macroestructural, con el fin de integrar los distintos fragmentos del discurso, los deícticos se emplean en fórmulas anafóricas (también presentes en el plano microestructural) o se opta con frecuencia por la denominada deíxis discursiva o textual. En ambos casos, se realiza la operación de mostrar, fundamentada en el origo, esto es, el punto cero para la interpretación de los deícticos. Debido a la inestabilidad de las coordenadas personales, temporales y espaciales de los actos de comunicación por escrito, el ego-hic-nunc de la situación comunicativa se ubica directamente en el propio texto, el cual es percibido por los interlocutores como un espacio común que da cabida tanto al emisor como al receptor del mensaje. De esta forma, no solo son interpretables con exactitud los deícticos espaciales empleados 
en los mecanismos cohesivos, sino que además el origo constituye un punto adicional de anclaje para las distintas unidades discursivas que contribuye a reforzar la integridad textual. Asimismo, debido a que el origo garantiza una interpretación precisa de los deícticos, estos, a su vez, pueden focalizar la atención del destinatario del mensaje en determinados elementos textuales.

El valor mostrativo y, en menor medida, el origo intratextual junto con la capacidad de focalización, persisten también en los recursos cohesivos por excelencia, esto es, los marcadores discursivos, pero principalmente en su variante analítica con demostrativos. Los marcadores de origen temporal suelen ser sintéticos y al asumir dos funciones, la conectiva y la lógica, se alejan de sus valores primarios.

De los casos descritos se desprende que, por su persistente valor mostrativo y su remisión al origo textual, los deícticos en recursos cohesivos empleados en formas de comunicación realizadas en el canal escrito entrelazan el texto con el cotexto, de la misma forma que otros usos deícticos crean el vínculo entre lo lingüístico y el contexto situacional.

\section{Bibliografía}

BEAUGRANDE, de R. A., DRESSLER, W. U. (1990), Wstęp do lingwistyki tekstu, PWN, Warszawa.

BELLERT, I. (1971), “O pewnym warunku spójności”, en: Mayenowa, R. (red.), O spójności tekstu, Ossolineum, Wrocław, pp. 47-81.

BENVENISTE, É. (1966), Problèmes de linguistique générale, Gallimard, Paris.

BÜHLER, K. (2004 [1934]), Teoria języka, Universitas, Kraków.

CASADO VELARDE, M. (1993), Introducción a la gramática del texto del español, Arco/Libros, Madrid.

DIJK VAN, T. A. (1988), Texto y contexto. Semántica y pragmática del discurso, Cátedra, Madrid.

DUSZAK, A. (1998), Tekst, dyskurs, komunikacja międzykulturowa, PWN, Warszawa. 
EGUREN, L. J. (1999), "Pronombres y adverbios demostrativos. Las relaciones deícticas", en: Bosque I., Demonte, V. (dirs.), Gramática descriptiva de la lengua española, vol. 1, Espasa-Calpe, Madrid, pp. 929-972.

ESCAVY ZAMORA, R. (2009), Pragmática y textualidad, Universidad de Murcia, Murcia.

FERNÁNDEZ RAMÍREZ, S. (1987), Gramática española, vol. 3.2: El pronombre, Arco/Libros, Madrid.

FILLMORE, Ch. J. (1997), Lectures on deixis, CSLI, Stanford.

FUENTES RODRÍGUEZ, C. (1996), La sintaxis de los relacionantes supraoracionales, Arco/Libros, Madrid.

GARCÍA SALIDO, M. (2011), "La distinción deíxis/anáfora y su aplicación a las formas de persona del español", Revista de Filología Española, XCI, 91 (1), pp. 65-88, [on-line] http://dx.doi.org/10.3989/rfe.2011.v91.i1.216. GONZÁLEZ RUIZ, R. (2009), "Algunas notas en torno a un mecanismo de cohesión textual: la anáfora conceptual”, en: Pena Ibáñez, M.A., González Pérez, R. (coords.), Estudios sobre el texto. Nuevos enfoques y propuestas, Peter Lang, Frankfurt am Main, pp. 247-278.

GRICE, P. (1980), "Logika a konwersacja” en: Stanosz, B. (red.) Język w świetle nauki, Czytelnik, Warszawa, pp. 91-114.

HALLIDAY, M. A. K., HASAN, R. (1984), Cohesion in English, Longman, London-New York.

LAMÍQUIZ, V. (1983), Lingüistica española, Publicaciones de la Universidad de Sevilla, Sevilla.

LEWANDOWSKI, T. (1995), Diccionario de lingüistica, Cátedra, Madrid.

LOZANO, J, PEÑA-MARÍN, C., ABRIL, G. (1993), Análisis del discurso, Cátedra, Madrid.

PEIRCE, Ch. S. (1997), Wybór pism semiotycznych, Znak-Język-Rzeczywistość: Polskie Towarzystwo Semiotyczne, Warszawa.

PORTOLÉS, J. (2001), Marcadores del discurso, Ariel, Barcelona.

PORTOLÉS LÁZARO, J., MARTÍN ZORRAQUINO, M. A. (1999), "Los marcadores del discurso", en: Bosque, I., Demonte, V. (dirs.), Gramática descriptiva de la lengua española, vol. 3, Espasa-Calpe, Madrid, pp. 4051-4214.

RAUH, G. (1983), “Aspects of Deixis”, en: Rauh, G. (ed.), Essays on Deixis, Narr, Tübingen, pp. 9-60. 
Real Academia Española, Asociación de Academias de la Lengua Española (2009), Nueva gramática de la lengua española, Espasa, Madrid.

ROJO, G., VEIGA, A. (1999), "El tiempo verbal. Los tiempos simples", en: Bosque, I., Demonte, V. (dirs.), Gramática descriptiva de la lengua española, vol. 2, Espasa-Calpe, Madrid, pp. 2867- 2934.

VICENTE MATEU, J. A. (1994), La deíxis. Egocentrismo y subjetividad en el lenguaje, Secretariado de Publicaciones de la Universidad de Murcia, Murcia.

ZYDEK-BEDNARCZUK, U. (2005), Wprowadzenie do lingwistycznej analizy tekstu, Universitas, Kraków. 